\title{
Modeling Of Subscriber Station Energy Consumption Network 802.16
}

\author{
M. Yudha Al Hakim \\ Department Of Electrical Engineering, University Of North Sumatra, Jl. Dr. Mansur No. 9 Padang Bulan, Kec. \\ Medan Baru, Kota Medan 20222
}

\begin{tabular}{|c|c|}
\hline ARTICLE INFO & ABSTRACT \\
\hline Article history: & Worldwide Interoperability for Microwave Access (WiMAX) is a \\
\hline $\begin{array}{r}\text { Received Aug 04, } 2021 \\
\text { Revised Sep 08, } 2021 \\
\text { Accepted Oct 30, } 2021\end{array}$ & $\begin{array}{l}\text { Broadband Wireless Access (BWA) technology that has high speed } \\
\text { and wide access for multimedia communication. The reception of } \\
\text { quality video or voice packets at the receiver is related to how } \\
\text { efficient the energy consumption is sent by the Subscriber Station }\end{array}$ \\
\hline $\begin{array}{r}\text { Keywords: } \\
\text { Wi Max } \\
\text { Mathematical Modeling } \\
\text { Energy Consumption } \\
\text { NS-2 }\end{array}$ & $\begin{array}{l}\text { energy consumption is needed. One way to calculate energy } \\
\text { consumption at a WiMAX subscriber station is by using } \\
\text { mathematical modeling. This final project is modeling energy } \\
\text { consumption in WiMAX. From the simulation, it is found that the } \\
\text { change in the bit rate affects the energy consumption of the } \\
\text { subscriber station. Through simulation, training data is generated to } \\
\text { obtain a mathematical model. The mathematical model contains the } \\
\text { components of the state duration and the level of energy } \\
\text { consumption. Mathematical models are then used to predict energy } \\
\text { consumption in WiMAX. The model is tested through the generation } \\
\text { of test data. The test results through simulation showthe percentage } \\
\text { deviation of the average energy consumption of training data with } \\
\text { mathematical modeling on average is } 0.180 \% \text {. Meanwhile, the } \\
\text { energy consumption of test data and mathematical models has an } \\
\text { average deviation of } 0.187 \% \text { and } 0.191 \% \text {. The least energy } \\
\text { consumption is generated when the MAC Initialization state (state i0) } \\
\text { is } 0.001 \text { Joule, while the highest energy consumption is the Uplink } \\
\text { Frame state (state i14) of } 101.017226 \text { Joule. }\end{array}$ \\
\hline
\end{tabular}

This is an open access article under the CC BY-NC license.

\section{Corresponding Author:}

M. Yudha Al Hakim,

Department Electrical Engineering,

University Of North Sumatra,

JI. Dr. Mansur No. 9 Padang Bulan, Kec. Medan Baru, Kota Medan 20222.

Email : yudhaalhakim@gmail.com

\section{INTRODUCTION}

Worldwide Interoperability for Microwave Access (WiMAX) is a Broadband Wireless Access (BWA) technology that has a high and wide access speed and is a technology based on the IEE standard, namely 802.16 WirelessMAN. WiMAX technology is designed to meet the needs of Quality of Service (QoS) on uplink and downlink connections .

Currently, multimedia communication is a necessity for the wider community. For example, real-time communication via skype, one-way non-real-time communication such as youtube videos. WiMAX devices support high speed requirements for multimedia access such as video streaming . 
If the transmission capacity is adequate, it is projected that multimedia communication between mobile device users in the future will increase.

The reception of quality video or voice packets at the receiver is related to how strong the signal emitted by the Base Station (BS) is received by the Subscriber Station (SS). Especially if the SS is in a moving position, where there will be changes in the radio wave propagation media, changes in obstacles, changes in indoor/outdoor conditions that cause the received signal to vary. Amplifying the signal at the receiver means increasing the signal to noise ratio which allows a decrease in the detected bit error rate of the signal, which in turn improves system performance [1].

Mobile communication devices use batteries as their energy source. The running of all applications depends on the availability of battery energy. All of these applications consume a large amount of battery energy because they involve large-capacity data transmission.

\section{RESEARCH METHOD}

The research method adopted is as follows:

a. Study of literature

Literature study in the form of literature review of books or journals as a theoretical basis.

b. Design and Simulation

The author models the energy consumption of 802.16 network devices (WiMAX) by connecting the existing energy consumption model and the quantity of device states both when transmitting, receiving and idle with the $\mathrm{C}_{++}$programming language and simulate using Network Simulator 2 Software.

c. Analysis

The author analyzes the training data and test data. Training data is used to form a mathematical model of energy consumption and test data is used to test the mathematical model.

d. Conclusion

Conclusions are drawn from the results of analysis and calculations. This conclusion is the answer to the problems analyzed. In addition, suggestions will also be given as input related to what has been researched.

\section{RESULTS AND DISCUSSIONS}

This chapter analyzes the simulation results generated in the simulation in NS-2. The analysis of the simulation results is in the form of training data to form a mathematical model of energy consumption and test data to test the mathematical model.

\subsection{Simulation Results}

\section{a. Energy Consumption Data Training}

Training data is data used to form a mathematical model of energy consumption. The training data is obtained by setting the subscriber station to send data at a constant bit rate of $40,000 \mathrm{bps}-$ 680,000 bps. From the simulation, energy consumption for training data is obtained as shown in Figure1.

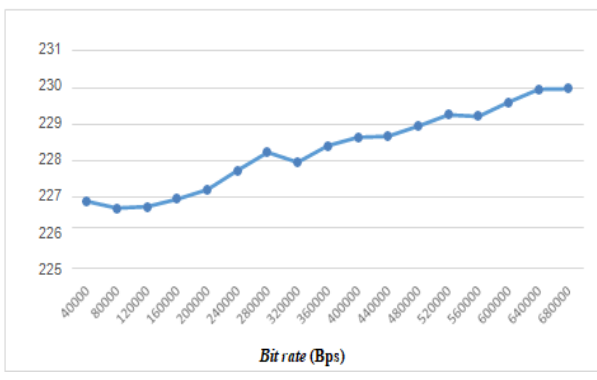

Figure 1. Energy Consumption Data Training 


\section{b. Energy Consumption Test Data}

Test data is data used to test the mathematical model of energy consumption. Here there are two test data used, the first test data is obtained by setting the subscriber station to send constant bit rate data from $56,000 \mathrm{Bps}-696,000 \mathrm{Bps}$. From the simulation, energy consumption is obtained for the test data first as in Figure 2.

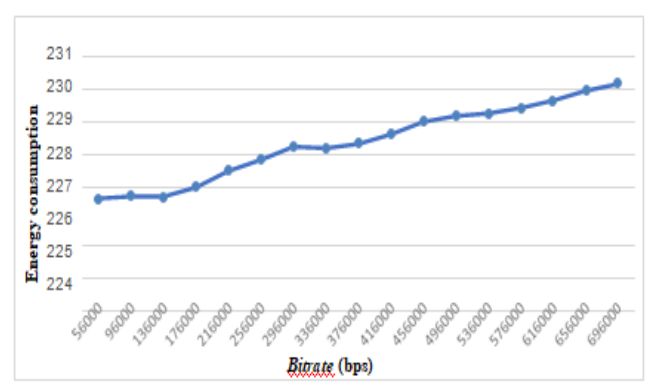

Figure 2. First Test Data Energy Consumption

The second test data is obtained by setting the subscriber station to send constant bit rate data from $64,000 \mathrm{Bps}-704,000 \mathrm{Bps}$. From the simulation, the energy consumption for the second test data is obtained as shown in Figure 3.

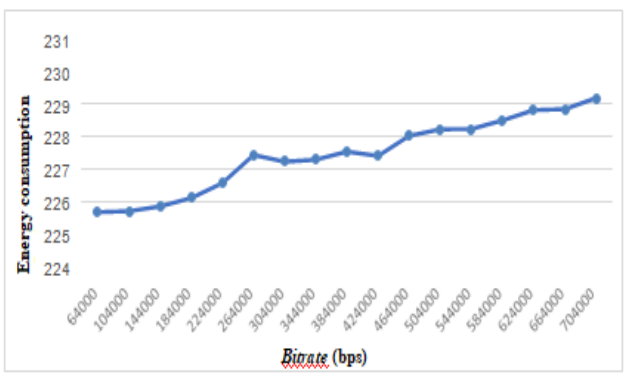

Figure 3. Second Test Data Energy Consumption

\subsection{Training Data Analysis}

\section{a. Duration of State on WiMAX Frame}

The type of state or state of the WiMAX device and the total duration of the state in sending data from the subscriber station to the WiMAX base station during the simulation observation period of 241 seconds for a sample bit rate of 40,000 Bps -

680,000 Bps is shown in Table1. The state duration value in Table 4.1 is the state duration which is constant for all bit rate values.

Table 1. Total State Duration at Sample Bit Rate 40,000 Bps $-680,000$ Bps

\begin{tabular}{cccc}
\hline Index Duration & State Name & Power Level & Total Duration(s) \\
\hline i0 & MAC initialization & TurnOn & 0.001 \\
i1 & MAC settings & idlePower & 0.000263 \\
i2 & DL-MAP Processing & DLPower & 1.411993 \\
i3 & DCD Processing & idlePower & 0.005981 \\
i4 & UCD Processing & idlePower & 0.004005 \\
i5 & Ranging processing & recPower & 0.000026 \\
i6 & Registration processing & idlePower & 0.00005 \\
i7 & NBR_ADV . Processing & idlePower & 0.003587 \\
\hline
\end{tabular}


Figure 4 shows the state duration condition which is constant at each bit rate traffic, while shows the change in state duration at each bit rate traffic. For each state duration that changes with the bit rate, a regression approach is used to generate trend equations. The trends involved are Exponential, Linear, Logarithmic, Polynomial and are selected which has the highest R2.

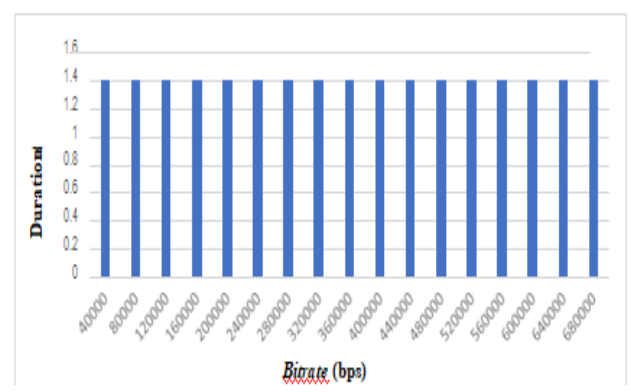

Figure 4. Constant Duration of State i2 in Every Bit Rate Traffic

State i8 is the outgoing packet processing state changes with bit rate with the rate of change decreasing with bit rate.

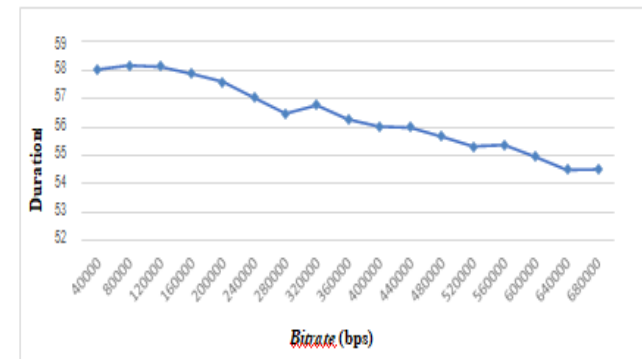

Figure 5. The Duration of State i8 that Changes at Every Bit Rate of Traffic

State i9, which is the state of sending packets to the physical layer, changes with the bit rate with an increasing rate of change with the bit rate.

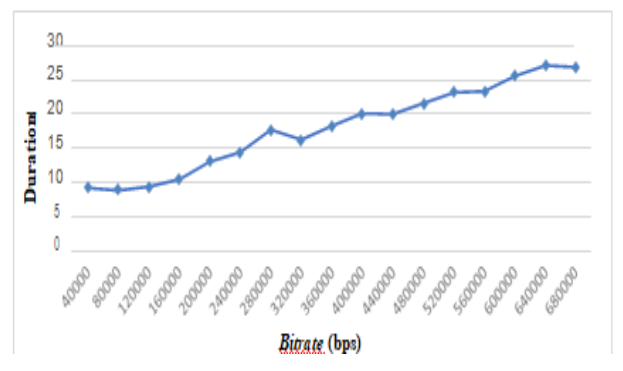

Figure 6. The Duration of State i9 that Changes at Every Bit Rate of Traffic

State 110 is the processing state of incoming packets changing with the bit rate with the rate of change decreasing with the bit rate. 


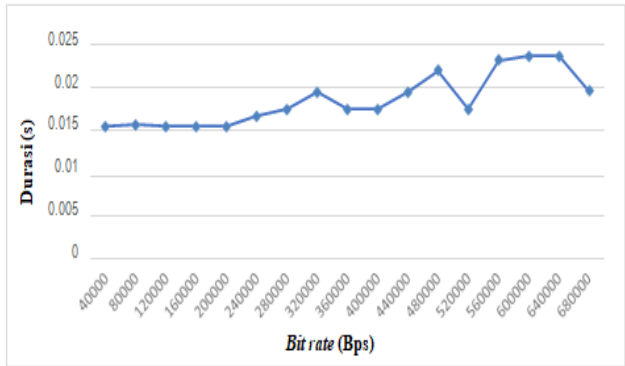

Figure 7. The Duration of State $\mathrm{i} 10$ that Changes in Every Bit Rate of Traffic

State $\mathrm{i} 11$ is the processing state of the received packet changing with the bit rate with the rate of change increasing with the bit rate.

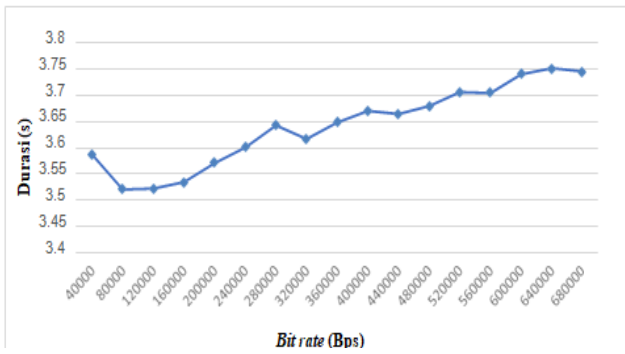

Figure 8. The Duration of State $\mathrm{i} 11$ that Changes at Every Bit Rate of Traffic

State 112 is UL_MAP processing state changes with bit rate with the rate of change increasing with the bit rate.

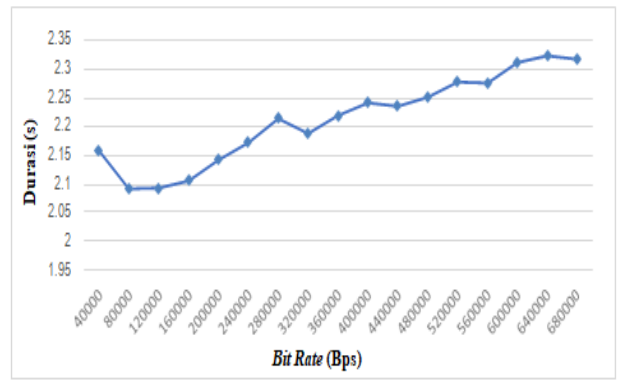

Figure 9. i12 State Duration that Changes at Every Bit Rate Traffic

State 113 is the update state when changing with the bit rate with the rate of change decreasing with the bit rate. 


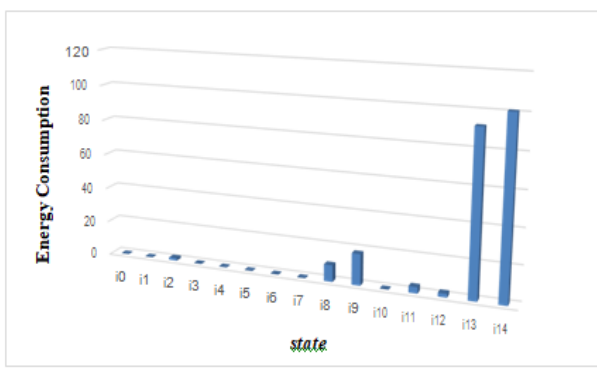

Figure 10. Energy Consumption in Each State

The graph above shows that in each state, the energy consumption produced is different. This is influenced by the number of durations that exist in each state. In the graph above, it can be seen that the least energy consumption generated during the MAC Initialization state (state i0) is 0.001 Joule, while the highest energy consumption is the Uplink Frame state (state i14) of 101.017226 Joule.

\subsection{Energy Consumption in Each State}

The energy consumption in each state on the WiMAX device is shown in Table 2.

Table 2. Energy Consumption in Each State

\begin{tabular}{cc}
\hline state & Energy Consumption (Joule) \\
\hline i0 & 0.001 \\
i1 & 0.00001578 \\
i2 & 1.411993 \\
i3 & 0.00035886 \\
i4 & 0.0002403 \\
i5 & 0.00000182 \\
i6 & 0.0000003 \\
i7 & 0.00021522 \\
i8 & 9.58509002 \\
i9 & 17.97881729 \\
i10 & 0.001294045 \\
i11 & 3.641454 \\
i12 & 2.214180353 \\
i13 & 92.45369012 \\
i14 & 101.017226 \\
\hline
\end{tabular}

\subsection{The graph of energy consumption in each state can be seen in Figure 13}

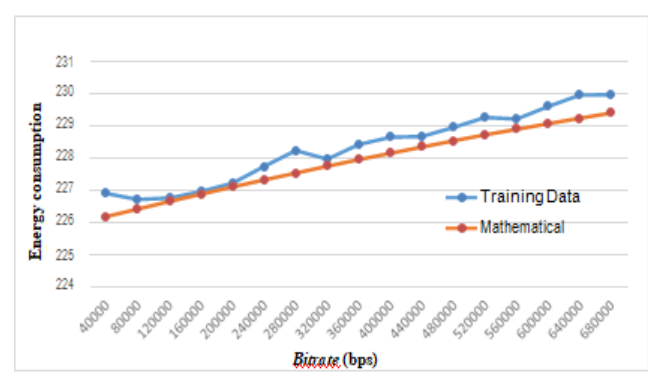

Figure 13. Comparison of Mathematical Models with Training Data

The level of energy consumption is affected by changes in the bit rate with respect to duration. The greater the bit rate of traffic, the greater the energy consumption. From Picture 13 it can be 
seen that the level of comparison value of energy consumption in the training data is greater than the value of energy consumption carried out by mathematical modeling. The percentage deviation of energy consumption of training data with mathematical modeling is an average of $0.180 \%$. The pattern of energy consumption on the bit rate generated by the training data with the results of mathematical modeling is not much different.

Changes in the bit rate affect the energy consumption of the subscriber station. The higher the bit rate, the more data will be sent by the subscriber station to the base station. Therefore, the more processes performed by the subscriber station, the greater the energy expended by the subscriber station.

\subsection{Comparison of Mathematical Models with Data Test}

The comparison of the mathematical model with the first test data is shown in Figure11.

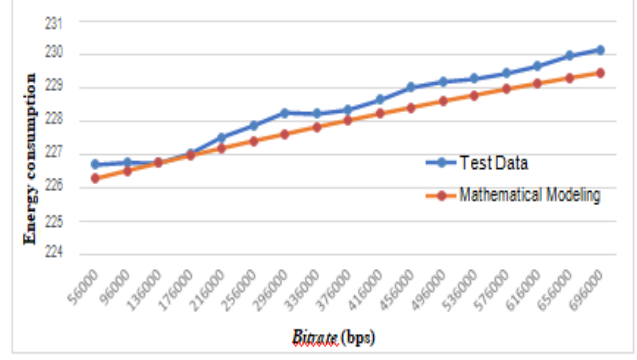

Figure 11. Comparison of Mathematical Models with Test Data

First From Figure 14 it can be seen that the energy consumption in the first test data is greater than the energy consumption carried out by a mathematical model. The percentage deviation of energy consumption in the first test data with mathematical modeling is an average of $0.187 \%$. The pattern of energy consumption on the bit rate generated by the first test data with the results of mathematical modeling is not much different. 12.

Then the comparison of the mathematical model with the second test data is shown in Figure

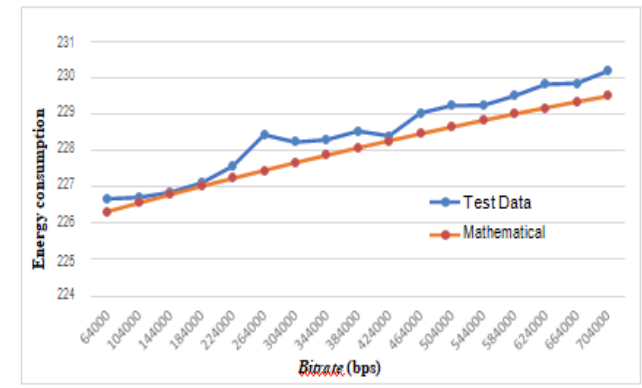

Figure 12. Comparison of the Mathematical Model with the Second Test Data

From Figure 15 it can be seen that the energy consumption in the second test data is greater than the energy consumption carried out by a mathematical model. The percentage deviation of energy consumption of the second test data with mathematical modeling is an average of $0.191 \%$. The pattern of energy consumption on the bit rate produced by the second test data with the results of mathematical modeling is not much different.

\section{CONCLUSION}


The mathematical model is derived from the duration value of each state (either constant or changing with the bit rate) and the power consumption level of each state, resulting in a mathematical model,

The least energy consumption is generated when the MAC Initialization state (state i0) is 0.001 Joule, while the highest energy consumption is the Uplink Frame state (state i14) of 101.017226 Joule.

Comparison of the resulting mathematical model to the test data resulted in an average deviation of $0.187 \%$ and $0.191 \%$.

\section{REFERENCES}

Golmie, N., et al. 2009. The WiMAX System Level Simulator NS-2 MAC+PHY Add-On for WiMAX (IEEE 802.16).

Perrucci, Gian Paolo., et al. 2008. "Energy Saving Strategies for Mobile Devices using Wake-up Signals." MobiMedia.

Henny, Januarti., et al. 2011. "Simulasi dan Analisis Algoritma Penjadwalan MSIR dan TRS+MSIR untuk Kelas RTPS QOS pada WiMAX (Simulation and Analysis of Algorithm Scheduling MSIR and TRS+MSIR for QOS RTPS Class In WiMAX)." Universitas Telkom.

Bezerra, Nibia S., et al. 2010. "Modelling Power Consumption in IEEE 802.16e WiMAX Mobile Nodes." The 7th International Telecommunications Symposium . ITS.

Abinader Jr, Fuad M., et al. 2012. "Evaluation of Joint Sleep and Idle Mode in IEEE 802.16e WIMAX." IJCSI International Journal of Computer Science Issues. 540-541.

Issariyakul, Teerawat., dan Ekram Hossain. 2012. Introduction to Network Simulator NS2. New York: Springer Science+Business Media.

Suherman. 2013. "A Novel Approach for Implementing Worldwide Interoperability for Microwave Access for Video Surveillance." (Doctoral dissertation, De Montfort University).

Febrinal., et al. 2010. "Pembuatan Tools untuk Perancangan Jaringan WiMAX / IEEE 802.16." Universitas Telkom.

Suherman. 2016. "Reduksi Konsumsi Energi pada Subscriber Station WiMAX Melalui Pengaturan Beban Protokol Transport." The 4th National Conference on Industrial Electrical and Electronics (NCIEE). Medan.

Suherman., et al. 2015. "A Transport Layer Protocol for Uplink WiMAX Video Streaming." International Journal of Multimedia and Ubiquitous Engineering. Medan: SERSC.

Ispriyanti, Dwi. 2007. "Pendekatan Regresi untuk Analisis Ragam Klasifikasi Dua-Arah." UNDIP. 